\title{
Development and Testing of a Laboratory Scale Paste Thickener
}

\author{
R.H. Olcay Barreda Mining Engineering Department, Universidade Federal de Minas Gerais, Brazil \\ A.C. de Araujo Mining Engineering Department, Universidade Federal de Minas Gerais, Brazil \\ G.E.S. Valadão Mining Engineering Department, Universidade Federal de Minas Gerais, Brazil
}

C.A. Hernández Engineering Department, Universidad Arturo Prat, Chile

\begin{abstract}
The major objective of this study was the design, construction and testing of a laboratory scale paste thickener. This unit has a modular construction and can be operated on a totally batch mode or as a fully continuous thickener. The thickener was constructed in Plexiglas in order to allow the direct observation of the slurry behaviour inside the equipment. It has two modules reaching a maximum height of $1.2 \mathrm{~m}$ with $10 \mathrm{~cm}$ of internal diameter. It still makes use of a system for taking samples with orifices of $1 \mathrm{~cm}$ of internal diameter and equally spaced in the vertical axes by $9 \mathrm{~cm}$. The mineral pastes produced by the equipment were characterised for their rheological properties by means the determination of: viscosity (viscometry), consistency (slump test), fluidity (flume test) and yield stress measurements. The best result without the addition of flocculant in the tests, with the recirculation of the pulp and a residence time of 10 min, was reached when the slurry was taken from orifice number 3 to orifice 1 . The paste reached $55.6 \%$ of solids by weight under this testing condition. Considering the addition of flocculants the best result was achieved with recirculation of the slurry from orifice number 4 to orifice number 1 . This paste reached 53\% of solids by weight. Employing two modules of the thickener, the final paste with recirculation reached $56.7 \%$ of solids by weight.
\end{abstract}

\section{Introduction}

According to Araujo et al. (2003) and Jewell (2002), a mineral paste is defined as a fine particle system that presents itself as a homogeneous fluid in which segregation of particles do not occur as well as any significant water drainage is present. As a result, higher angles of disposal are obtained, for example in the range from 2 to $5 \%$, representing an important gain in terms of volumes per area of disposal (Araujo et al., 2003). Some important characteristics that have to be considered for tailings disposal are height of slump, repose angle, viscosity behaviour and shear stress. Currently the production of mineral paste can be carried out by means of thickeners or filters for backfill (underground mining) and surface disposal. The use of paste thickeners represents an attractive alternative to the filtration operation. Thickeners are utilised, for example, for the production of red mud paste in Australia (Slottee et al., 2005). The DeBeers paste thickener of the CTP plant, in Kimberley, is an example of disposal of paste using a surface disposal system known as stacking (Houman and Johnson, 2003). Research programmes to understand the complex mechanisms involved in the production mineral pastes are presently in high demand.

\section{Methodology}

\subsection{Materials}

The mineral sample represents a tailing obtained from the mineral processing of the manganese ore and came from western region of Brazil. The specific gravity, the size distribution, the chemical and mineralogical compositions, and specific surface area were determined for the sample.

\subsection{Experimental methodology}

The samples were received in the form of slurry. The liquid component (water) was separated from of the solid by using filtration. The solid was dried at a $100^{\circ} \mathrm{C}$. Representative samples were obtained for the 
determination of different physical and chemical properties of the material. Table 1 presents the techniques utilised in this case.

Table 1 Techniques utilised for determination physical and chemical properties of the material

\begin{tabular}{ll}
\hline Property & Technique \\
\hline Specific gravity & $\begin{array}{l}\text { Conventional picnometry (CP) } \\
\text { Gas picnometry (GP) }\end{array}$ \\
Size distribution & Laser diffraction \\
Chemical & X Ray fluorescence (XFR) \\
composition & Scanning electronic microscopy and microprobe analysis by EDS \\
Mineralogical & X Ray diffraction \\
composition & Infrared spectroscopy and SEM/EDS \\
Specific surface & BET nitrogen adsorption \\
area & Air permeability \\
\hline
\end{tabular}

The residence time necessary to the paste formation was determined by using graduated cylinders $(2000 \mathrm{~mL})$ with different initial solid percentages $(10 \%, 15 \%$ and $20 \%)$. The flocculant selection was carried out utilising graduated cylinder $(250 \mathrm{~mL})$ and three types of flocculant: anionic, cationic and non-ionic. The flocculants tested are indicated in Table 2.

The thickener developed herein is made of Plexiglass and has a modular system with two cylindrical modules having each one a length of $60 \mathrm{~cm}$ and $10 \mathrm{~cm}$ of internal diameter. It has a set of orifices that are used for sampling and/or slurry recirculation.

\section{Table 2 Tested flocculants}

\begin{tabular}{lll}
\hline Cationic & Anionic & Non-Ionic \\
\hline SC-492 & SA-130 & SN-100 \\
SC-496 & SA-110 & SN-300 \\
SC-494 & BA61BT & M-351 \\
BC-630 & M338 & - \\
- & M10 & - \\
\hline
\end{tabular}

The orifices have an internal diameter of $1 \mathrm{~cm}$ and the distance between them is $9 \mathrm{~cm}$. The orifices are enumerated of 1 up to 10 from bottom to the top. The underflow discharge is carried through a conical surface. An acrylic bar of $9 \mathrm{~cm}$ of diameter and length of $1.4 \mathrm{~m}$ was used for agitation in batch tests. For the continuous tests, agitation was performed using mechanical agitation of the slurry feed. Peristaltic pumps were also utilised for slurry feeding and recirculation. Figure 1 shows the equipment with two modules in continuous process operation and the system for sampling.

The conditions of the batch tests, when only one module was utilised, were as follows: feed with $15 \%$ solids $(\mathrm{w} / \mathrm{w})$, different volumes of slurry $(1000,2000,3000$ and $4000 \mathrm{~mL})$, and different residence times $(5,10$, 15 min), without flocculant. The influence of the flocculant (SN 300) addition was only verified for total volume of $4000 \mathrm{~mL}$.

The conditions of the batch tests, when two modules were utilised, were as follows: feed with $15 \%$ solids $(\mathrm{w} / \mathrm{w})$, without and with flocculant (SN 300) addition, different volumes of slurry $(5000,6000,7000 \mathrm{~mL})$, and residence time of $10 \mathrm{~min}$. 


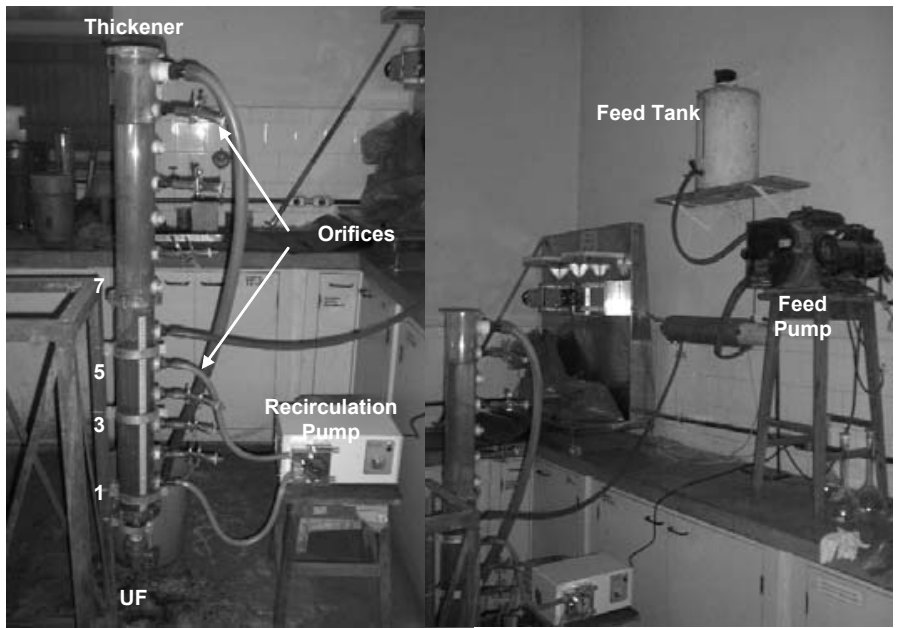

\section{Figure 1 Equipment with two modules in continuous process mode}

The conditions of the semi continuous tests when one module was used were slurry recirculation with different combinations, without and with flocculant (SN 300) addition, volume of $4000 \mathrm{~mL}$ and residence time of $10 \mathrm{~min}$. The conditions of the semi continuous tests when two modules were used were slurry recirculation with different combinations, without and with flocculant (SN 300) addition, volume of $7000 \mathrm{~mL}$ and residence time of $10 \mathrm{~min}$. The continuous tests with two modules $(7000 \mathrm{~mL})$ were carried out in presence of flocculant (SN 300) in dosages of 25, 50 and $75 \mathrm{~g} / \mathrm{t}$. The slurry was fed at two different heights (orifices 3 and 6 ) that correspond respectively to 27 and $54 \mathrm{~cm}$ height. The total running time was to $180 \mathrm{~min}$.

The mineral pastes were studied by means of slump test, flume test, and viscometry.

The slump tests (Clayton et al., 2003) were performed based on a Brazilian standard procedure (ABNT, 1998). It was utilised a cylinder with height of $10 \mathrm{~cm}$ and diameter of $10 \mathrm{~cm}$.

The flume tests were carried out using the apparatus with $100 \mathrm{~cm}$ of length, $20 \mathrm{~cm}$ of width, and $20 \mathrm{~cm}$ of height. The tested slopes were 1,2, and 3\%. The flume apparatus is shown in the Figure 2.

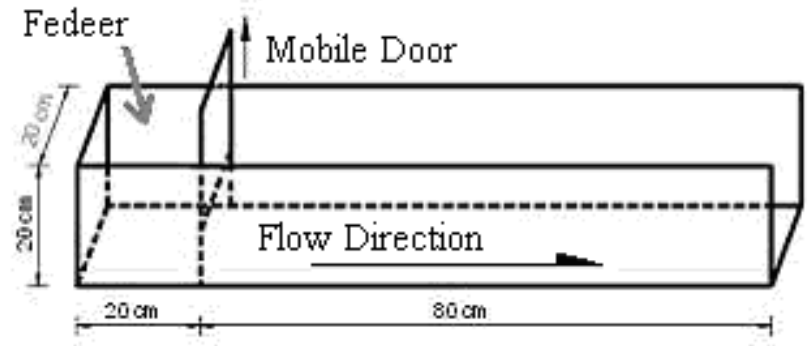

Figure 2 Flume apparatus (modified from Kwak et al., 2005)

A Brookfield DVIII viscosimeter and a Brookfield YR-1 rheometer were utilised for the determination of viscosity and yield stress, respectively.

\section{$3 \quad$ Results and discussion}

The values of specific gravity were $2.87 \mathrm{~g} / \mathrm{cm}^{3}$ (water picnometry), and $3.14 \mathrm{~g} / \mathrm{cm}^{3}$ (gas picnometry).

The size distribution of solid particles of mineral sample obtained by means of Sympatec (laser diffraction) equipment is shown in the Figure 3. 


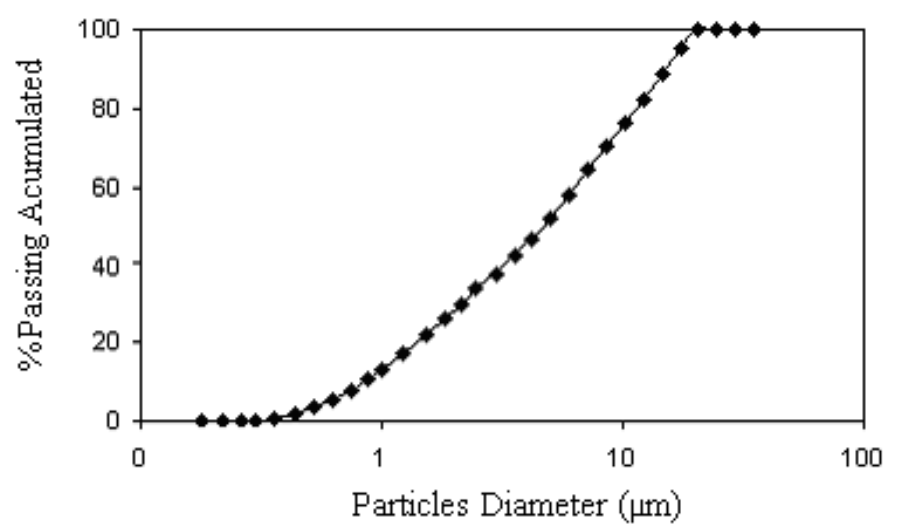

Figure 3 Size distribution of the solid particles of the mineral sample

Approximately $80 \%$ of the particles are smaller than $10 \mu \mathrm{m}$, that is, the material has high content of slimes.

The chemical analysis, presented on the Table 3, shows that the predominant elements are $\mathrm{Mn}, \mathrm{Si}, \mathrm{Al}$, and $\mathrm{Fe}$. The minor components are $\mathrm{Mg}, \mathrm{K}, \mathrm{Na}$, and $\mathrm{Ca}$.

\section{Table 3 Chemical analysis}

\begin{tabular}{ll}
\hline Element & (\% Weight) \\
\hline $\mathrm{Mn}$ & 21.87 \\
$\mathrm{Si}$ & 30.16 \\
$\mathrm{Al}$ & 28,04 \\
$\mathrm{Fe}$ & 18.77 \\
$\mathrm{Mg}$ & 0.00 \\
$\mathrm{~K}$ & 0.82 \\
$\mathrm{Na}$ & 0.23 \\
$\mathrm{Ca}$ & 0.11 \\
\hline
\end{tabular}

The X-ray diffraction and the infrared spectroscopy indicated chiefly the presence of pyrolusite $\left(\mathrm{MnO}_{2}\right)$ and kaolinite $\left(\mathrm{Al}_{2} \mathrm{Si}_{2} \mathrm{O}_{5}(\mathrm{OH})_{4}\right)$.

The specific surface area (SSA) was determined by means of two methods BET and Blaine. The values obtained are shown in the Table 4.

Table 4 Values of specific surface area (SSA) determined by BET e Blaine

\begin{tabular}{lll}
\hline Technique & BET & Blaine \\
\hline SSA $(\mathrm{m} 2 / \mathrm{g})$ & 28,963 & 0.893 \\
\hline
\end{tabular}

The results are not similar as expected. The obtained isotherm in the BET method indicated the multilayer adsorption, isotherm type III, hence that was not considered as a true measurement of this property for this sample.

Figure 4 presents the settling curves obtained from the batch tests (graduate cylinders of $2000 \mathrm{~mL}$ ) for 10,15 and $20 \%$ solids $(\mathrm{w} / \mathrm{w})$. The Table 5 indicates the settling rates obtained from this curves. The results indicate that the time to reach the compression point depends on the solids percentage. For $15 \%$ of solids, for example, the time is approximately $33 \mathrm{~min}$. The higher the percentage of solids the higher the settling rate. The value of $15 \%$ of solids was chosen for the further tests due to the interface being more clearly observed for this condition. 


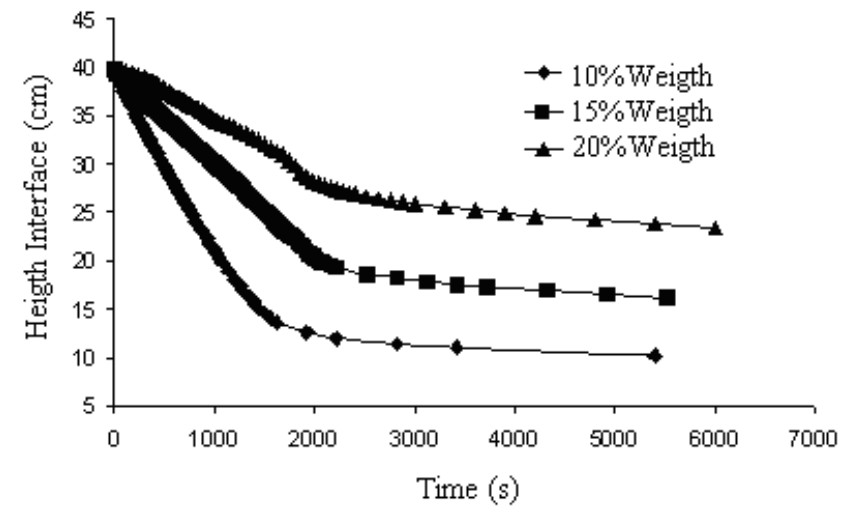

Figure 4 Settling curves obtained from batch tests (graduate cylinders of $2000 \mathrm{~mL}$ )

Table 5 Settling rates for $10 \%, 15 \%$ and $20 \%$ of solids without flocculant addition

\begin{tabular}{lll}
\hline \% Solids & Settling Rate $(\mathbf{c m} / \mathbf{s})$ & $\left.\mathbf{( r}^{\mathbf{2}}\right)$ \\
\hline 10 & $2.112 \times 10-2$ & 0.999 \\
15 & $1.067 \times 10-2$ & 0.991 \\
20 & $2.833 \times 10-3$ & 0.990 \\
\hline
\end{tabular}

Table 6 shows the values obtained for the settling rate at $15 \%$ of solids $(\mathrm{w} / \mathrm{w})$ in presence of the flocculants.

Table 6 Settling rate tests for cationic, anionic, and non-ionic flocculants

\begin{tabular}{llllll}
\hline $\begin{array}{l}\text { Cationic } \\
\text { Flocculant }\end{array}$ & $\begin{array}{l}\text { Rate } \\
(\mathbf{c m} / \mathbf{s})\end{array}$ & $\begin{array}{l}\text { Anionic } \\
\text { Flocculant }\end{array}$ & $\begin{array}{l}\text { Rate } \\
(\mathbf{c m} / \mathbf{s})\end{array}$ & $\begin{array}{l}\text { Non-Ionic } \\
\text { Flocculant }\end{array}$ & $\begin{array}{l}\text { Rate } \\
(\mathbf{c m} / \mathbf{s})\end{array}$ \\
\hline SC492 & 0.0332 & SA130 & 0.0775 & SN100 & 0.0587 \\
SC496 & 0.0335 & SA110 & 0.0407 & SN300 & 0.0622 \\
SC494 & 0.0239 & BA61BT & 0.0314 & M351 & 0.0287 \\
BC630 & 0.0465 & M338 & 0.0322 & & \\
& & M10 & 0.0422 & & \\
\hline
\end{tabular}

Flocculants BC 630, SA 130 and SN 300 were the best in each flocculant class. SN 300 was selected for further testing. Figure 5 presents the relationship between settling rate and flocculant dosage for SN 300 .

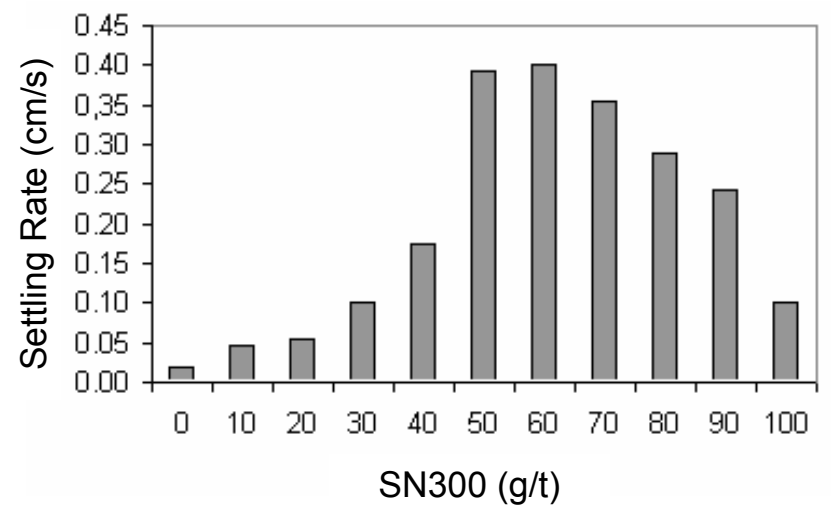

Figure 5 Settling rate as a function of dosage for SN 300

As seen in Figure 5, the highest settling rate is reached when flocculant dosage is the range from 50 to $60 \mathrm{~g} / \mathrm{t}$. 
Batch, semi batch and continuous settling tests employing the laboratory thickener are presented from this point on. Figures 6a presents results obtained with one module without the addition of flocculant and Figure $6 \mathrm{~b}$ the results of the influence of flocculant dosage on the final (underflow) percent solids.
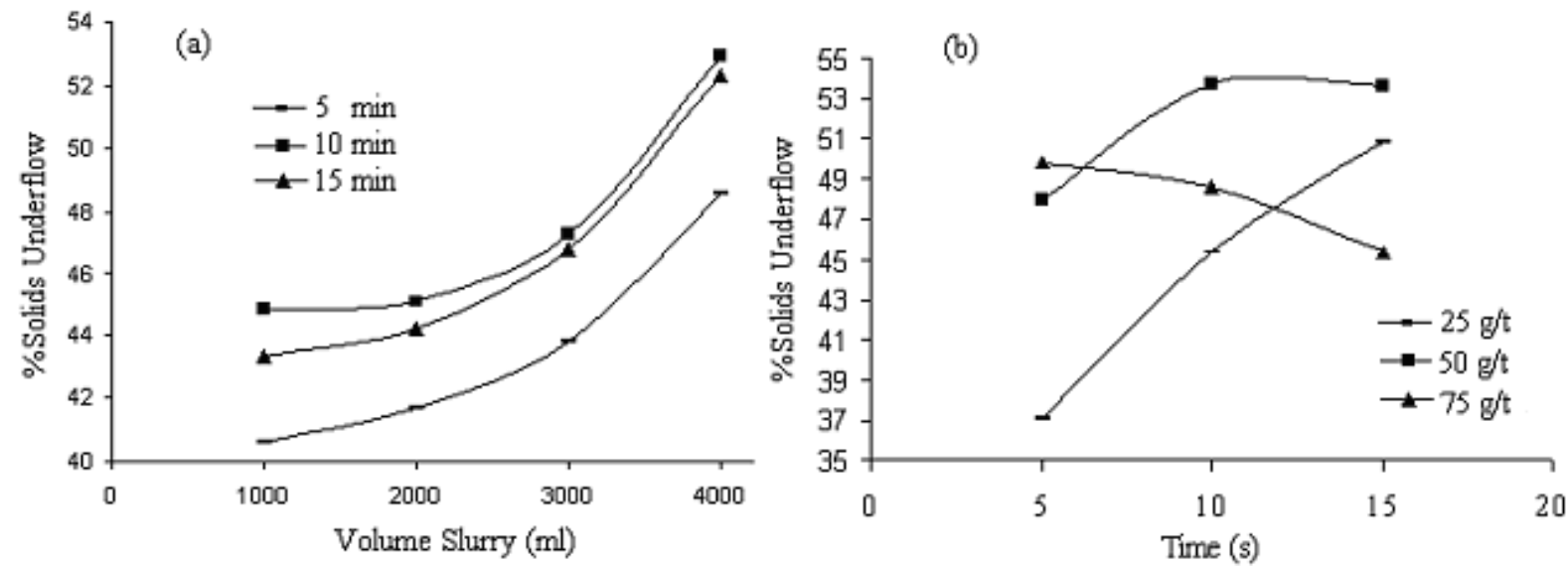

Figure 6 (a) Variation of \% solids in the underflow as a function of slurry volume for different values of residence time; (b) Variation of \% solids in underflow as a function of time for different values of flocculant dosages for a total slurry volume of $4000 \mathrm{~mL}$

Figure $6 \mathrm{a}$ indicates that the $\%$ solids of the underflow are larger as the slurry volume increases for different values of residence time. The best condition of operation was reached for a residence time of $10 \mathrm{~min}$ at a total slurry volume of $4000 \mathrm{~mL}$, with the underflow reaching $52.9 \%$ solids. The increase of the slurry content of 3.53 folds the initial solids concentration. Figure $6 \mathrm{~b}$ shows that underflow \% solids are larger as the residence time is increased for 25 and $50 \mathrm{~g} / \mathrm{t}$ of flocculant. For a higher flocculant dosage the underflow \% solids decreases. With the use of flocculants the highest \% solids reached was $53.7 \%$.

Semi-batch tests with one module with and without the use of SN300 flocculant are presented on Tables 9, 10 and 11. From Tables 9 and 10, it is clear that the best condition was achieved for slurry recirculation from orifice 3 to 1 without adding flocculant. With the addition of flocculant, as it can be seen on Table 9, the best condition took place with slurry recirculation from orifice 4 to orifice 1 when a final underflow of 53\% solids was reached.

Table 7 Underflow \% solids for $4000 \mathrm{~mL}$ of slurry and residence time of $10 \mathrm{~min}$

\begin{tabular}{lclllll}
\hline \multicolumn{6}{l}{ Combinations (Out $\rightarrow$ In) } \\
\hline \% solids of & $1 \rightarrow 2$ & $2 \rightarrow 1$ & $3 \rightarrow 1$ & $4 \rightarrow 1$ & $5 \rightarrow 1$ & $6 \rightarrow 1$ \\
underflow & 53.5 & 47.9 & 55.6 & 52.6 & 54.4 & 51.8 \\
\hline
\end{tabular}

Table 8 Underflow \% solids for other combination of orifices, $4000 \mathrm{~mL}$ of slurry and residence time of $10 \mathrm{~min}$

\begin{tabular}{lcccccl}
\hline \multicolumn{6}{l}{ Combinations (Out $\rightarrow$ In) } \\
\hline \% solids of & $3 \rightarrow 2$ & $4 \rightarrow 2$ & $5 \rightarrow 2$ & $4 \rightarrow 3$ & $5 \rightarrow 3$ & $5 \rightarrow 4$ \\
underflow & 50.9 & 52.2 & 52.9 & 53.6 & 54.5 & 55.3 \\
\hline
\end{tabular}


Table 9 Underflow \% solids with the addition of flocculant and slurry recirculation as indicated for $4000 \mathrm{~mL}$ of slurry and residence time of $10 \mathrm{~min}$

\begin{tabular}{lccc}
\hline \multicolumn{4}{l}{ Combinations (Out $\rightarrow$ In) } \\
\hline \% solids of & $2 \rightarrow 1$ & $3 \rightarrow 1$ & $4 \rightarrow 1$ \\
underflow & 52.7 & 47.5 & 53.0 \\
\hline
\end{tabular}

The results of underflow final \% solids for testing employing two modules are shown in Figure 7, with and without adding SN 300 as flocculant. Similar final \% solids for underflow were reached. Without flocculant, the final underflow was slightly higher in terms of its solids content reaching $56.2 \%$ in comparison to 55.8 with flocculant. The trend of the curves shown in Figure 7 can be related by a fifth order polynomial as shown on Equations (1) and (2).

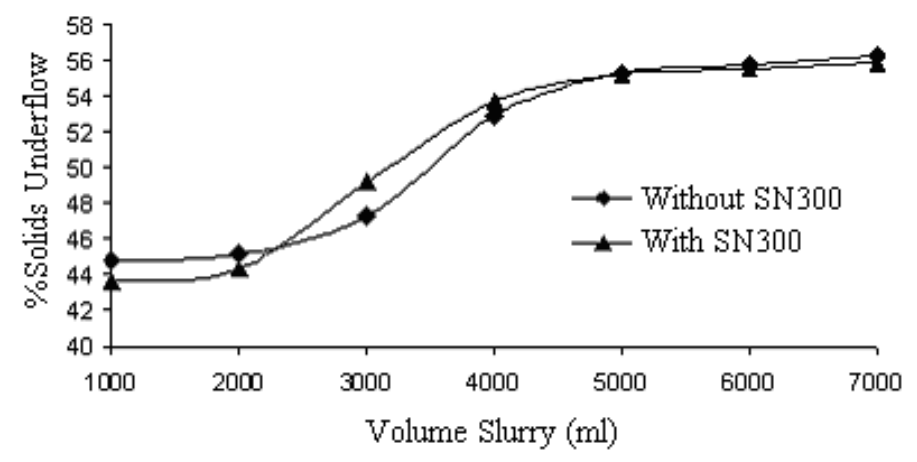

Figure 7 Variation of \% solids as a function of slurry volume for modules 1 and 2 together, with and without the addition of flocculant and 10 min of residence time

$$
\begin{aligned}
& \% S=4 \times 10^{-17} \times V^{5}-7 \times 10^{-13} \times V^{4}+4 \times 10^{-9} \times V^{3}-1 \times 10^{-5} \times V^{2}+0.0124 \times V+39.919 \\
& \% S=-1 \times 10^{-17} \times V^{5}+3 \times 10^{-13} \times V^{4}-3 \times 10^{-9} \times V^{3}+2 \times 10^{-5} \times V^{2}-0.0263 \times V+57.643
\end{aligned}
$$

where:

$$
\begin{aligned}
& \% \mathrm{~S} \quad=\% \text { solids in the underflow. } \\
& \mathrm{V} \quad=\text { slurry volume in the equipment. }
\end{aligned}
$$

Semi-batch tests with one and two modules, with and without addition of flocculant have their results summarised in Figures 9 and 10, respectively. In Figure 8, one can observe that the best condition in terms of underflow \% solids was reached with slurry recirculation from orifice 7 to 1 without flocculant addition. In Figure 9 the highest underflow \% solids was reached with slurry recirculation taking place from orifice 4 to orifice 1 . Under these conditions the final underflow solids content reached $53.7 \%$. For continuous operation, the highest value reached for the underflow \% solids was 56.1. The total testing time was 180 min. Figure 10 shows the results obtained at various operating times for a continuous mode.

Slump tests were performed for pastes from 47 to $59 \%$ solids (Figure 11). A slump of 50\% was attained at approximately $51 \%$ solids whereas a $20 \%$ slump was reached at approximately $56 \%$ solids.

Figure 12 summarises flume tests. Maximum repose angle was attained for approximately 55\% solids. 


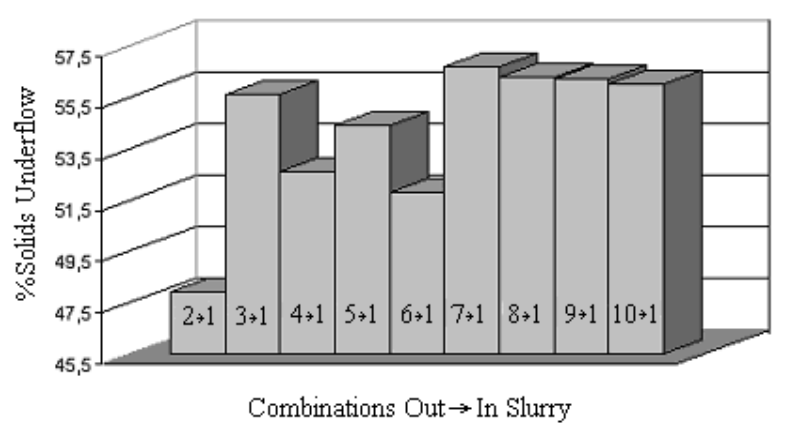

Figure 8 Variation of \% solids of the underflow as a function of different orifice combinations for a total residence time of $10 \mathrm{~min}$ and slurry volume of $7000 \mathrm{~mL}$ (two modules)

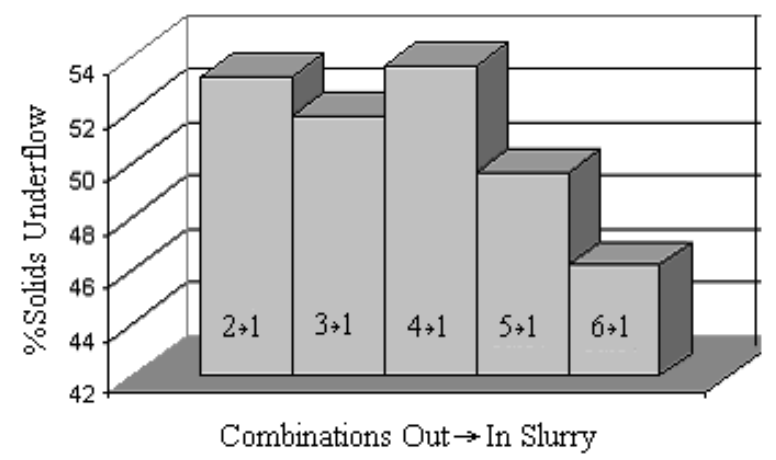

Figure 9 Variation of underflow \% solids as a function of different orifice combinations for 10 minutes of residence time and slurry volume of $7000 \mathrm{~mL}$, with $\mathrm{SN} 300$ addition

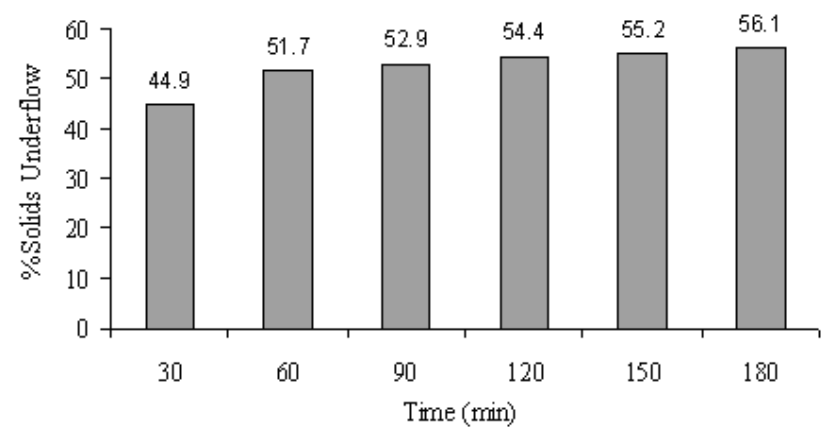

Figure 10 Variation of \% solids of the underflow as a function of total operating time for best overall conditions

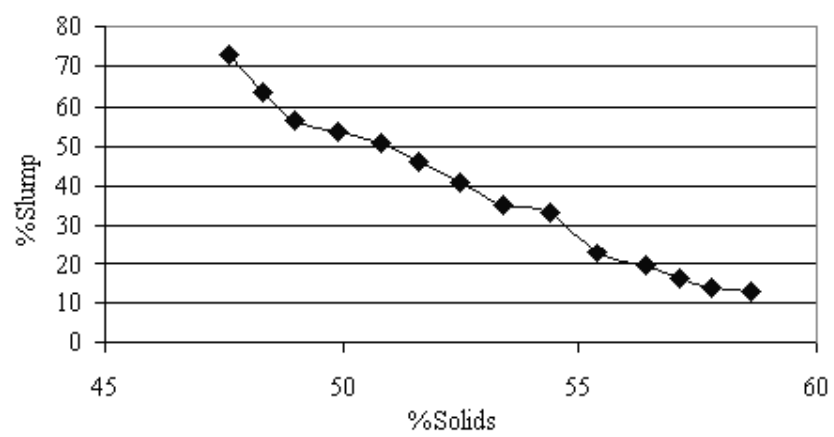

Figure 11 Percentage of slump as a function of paste $\%$ solids 


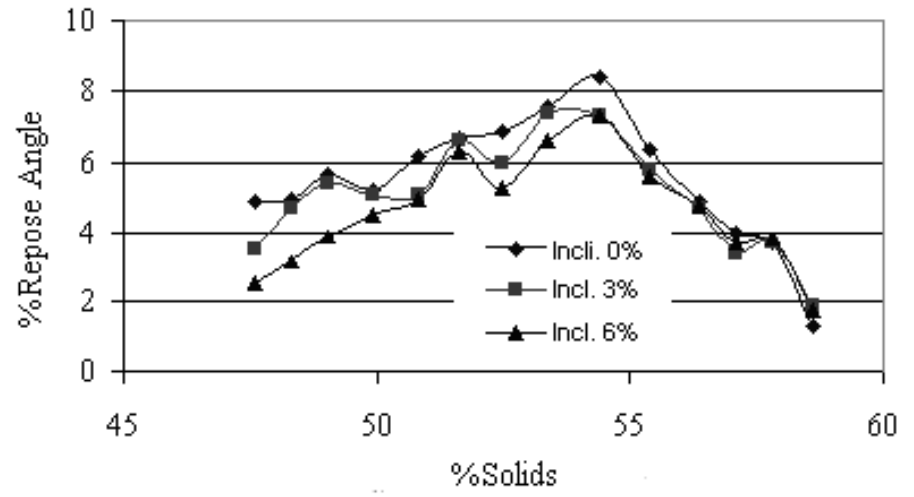

Figure 12 Repose angles as determined by flume tests

Figure 13 shows the rheological cycles for low (1-20-1), medium (1-100-1) and high (1-180-1) spindle rotation. Mixed thixotropic-rheotropic behaviour was observed, especially at the highest \% solids tested.

Figure 14 presents the results of yield stress (YS) for paste with 40, 45, 50 e 55\% solids. A polynomial equation of second order was found to give a good fit to data shown in Figure 14, as observed in Equation (3).

$$
\text { YS }=0.1936 \times(\% \text { solids })^{2}-14.598 \times(\% \text { solids })+315.46
$$

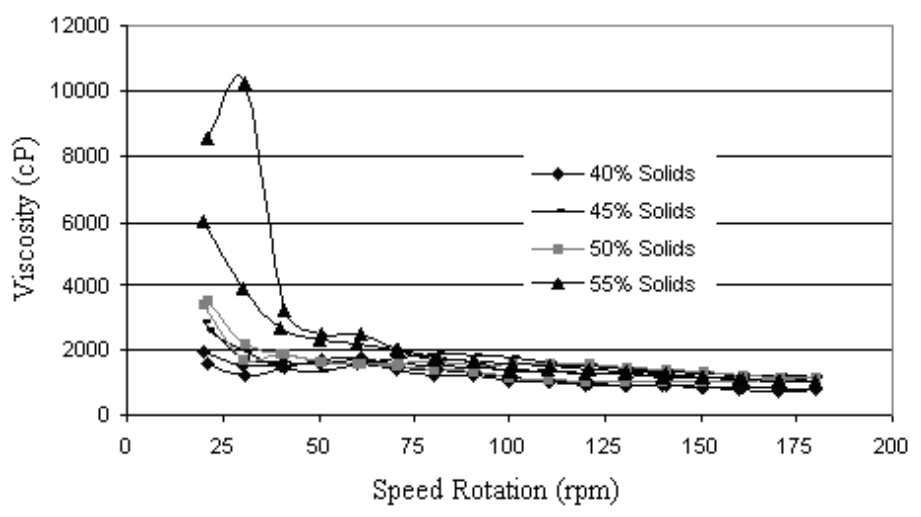

Figure 13 Rheological cycles - viscosity of pastes

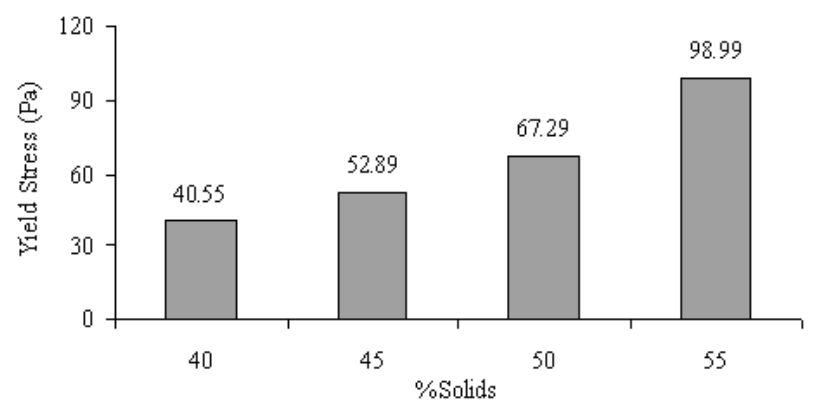

Figure 14 Yield stress for different solid contents of the pastes 


\section{Conclusions}

The minimum time for the slurry to reach compression is $2000 \mathrm{~s}$. The best flocculants for each class were BC 630 (cationic), SA 130 (anionic) and SN 300 (non-ionic).

The highest underflow \% solids for tests without the addition of flocculant, was reached for a residence time of $10 \mathrm{~min}$ with a total slurry volume of $4000 \mathrm{~mL}$ and recirculation from orifice 3 to orifice 1 . Under these conditions, the underflow weight percent reached $55.6 \%$. For the same conditions but with the use of flocculant and recirculation from orifice 4 to orifice 1, the final underflow presented $53 \%$ of solids.

For semi-batch tests with and without the addition of flocculant and for a slurry volume of $7000 \mathrm{~mL}$ the best operational condition was reached when slurry was recirculated from orifice 7 to orifice 1 with the final underflow reaching $56.7 \%$. When recirculation was from orifice 7 to orifice 1 , the final underflow reached $53.7 \%$ solids.

On continuous operation at a flocculant dosage of $50 \mathrm{~g} / \mathrm{t}$, the underflow reached $52.7 \%$ of solids.

Pastes are formed when the $\%$ solids reaches at least $45 \%(\mathrm{w} / \mathrm{w})$ for the tailings tested herein and slump tests showed less than $20 \%$ slump to occur for pastes with more than $55 \%$ solids. Flume tests showed slopes above $8^{\circ}$ for $54.4 \%$ solids at an equivalent $33.6 \%$ slump.

The pastes presented a mixed thixotropic-rheotropic behaviour. Yield stress increases with \% solids by weight.

\section{Acknowledgements}

The authors would like to express their thanks for the support from CNPq and FAPEMIG, Brazil. Many thanks to RDM-VALE for supplying the tailings sample.

\section{References}

ABNT - Associação Brasileira de Normas Técnicas (1998) Norma para concreto. Determinação de consistência pelo abatimento de cone - NBR NM 67, Rio de Janeiro, p. 18.

Araujo, A.C., Souza, C.C. and Amarante, S.C. (2003) Rejeitos adensados para disposição em superfície - nova tecnología em Minério de Ferro. IV Simpósio Brasileiro de Minério de Ferro, ABM, Ouro Preto, pp. 610-619.

Clayton, S., Grice, T.G. and. Boger, D.V. (2003) Analysis of the slump test for onsite yield stress measurement of mineral suspensions, International Journal of Mineral Processing, June 2003, pp. 3-21.

Houman, J. and Johnson, G. (2003) Commissioning and operation of the paste thickening farm at Kimberley combined treatment plant, 2003 International Seminar on Paste and Thickened Tailings, Australian Centre for Geomechanics, Perth, Australia, Section 12.

Jewell, R.J. (2002) Paste and thickened tailings in the Australian mining industry, High Density and Paste 2002 Seminar, Santiago, CD-ROM.

Kwak, M., James, D.F. and Klein, K.A. (2005) Flow Behaviour of tailings paste for surface disposal. International Journal of Mineral Processing, (available online: www.sciencedirect.com).

Slottee, S., Johnson, J. and Crozier, M. (2005) Paste thickening iron ore tailings, VI Simpósio Brasileiro de Minério de Ferro, ABM, Florianópolis, pp. 904-911. 